\title{
Simulation of a waiting system
}

\author{
Olga-Ioana Amariei, Codruța-Oana Hamat \\ This paper analyzes an existing production system in an industrial hall, \\ consisting of 11 machines (service stations) and 13 intermediate stocks \\ (queues), where 4 types of parts are processed and assembled, with the \\ aim of increasing production volume. The Queuing System Simulation \\ module of the WinQSB software is used, which allows the simulation of \\ waiting systems.
}

Keywords: queues, serving stations, average processing time, average waiting time, average stationary time, standard deviation

\section{Introduction}

Probability theory and mathematical statistics are inevitable in the analysis of simple or complex waiting systems, because there are constantly situations of uncertainty both in terms of time of arrival and duration of services [2].

Waiting, forming a "waiting line" or a "queue" is a common phenomenon in the activity of an organization [9].

The design of a "waiting" model implies the knowledge of some characteristics of the studied phenomenon regarding the average number of: units in the system, of the units about to be served, of units in the queue, of unoccupied stations, of units arriving in a given time as well as the average time: serving, waiting in the system and waiting in a line [8].

The basic process in models for waiting phenomena consists of units generated over time by an input source, which require to be served by one or more serving stations. Units that cannot be served immediately will form waiting lines or queues. The most commonly used serving discipline is FIFO (first come, first served) [1]. 


\section{Illustrative example}

The production system (fig.2) required to be analyzed consists of 11 machines (serving stations or servers) on which 4 types of parts are processed and assembled (R1 $\div$ R4).

Part R1 is processed on machines M1 and M5, and part R2 on machines M2 and M6, then a piece of each part type is assembled on machine M8 (Subassembly 1). Parts R3 and R4 are processed on machines $M 3$ and $M 4$, and then a piece of each part is assembled on machine M7 (Subassembly 2). On the M9 machine, the two subassemblies are assembled, which are then processed on the M10 and M11 machines, both machines being identical.

If a machine from the first six (M1 $\div \mathrm{M} 6)$ is occupied, the parts wait for the release of that machine in the container corresponding to that machine, the socalled queues (intermediate stocks) between different jobs. There are also queues after the machines where the subassemblies are made and the assembly, more precisely, the M7, M8 and M9 machines. In the case of M10 and M11 machines, processing is carried out on any of them which are available.

It is considered that all parts are processed and assembled according to the FIFO serving discipline, and the storage space for the parts to be processed and assembled is limited and therefore the maximum capacity for each queue, which is equal to 200 , is specified.

The duration of the time intervals between two consecutive arrivals of parts $\mathrm{R} 1$ to machine $\mathrm{M} 1$ is a uniformly distributed probabilistic quantity between 0.5 and 0.6 hours. The duration of the time intervals between two consecutive arrivals of parts R2 to the machine M2 is a probabilistic quantity with normal distribution with an average of 0.6 hours and the standard deviation 0.2 hours. The duration of the time intervals between two consecutive arrivals of parts R3 at machine M3 is a uniformly distributed probabilistic quantity between 0.5 and 0.6 hours. The duration of the time intervals between two consecutive arrivals of parts R4 to the machine M4 is a probabilistic quantity with normal distribution with an average of 0.6 hours and the standard deviation 0.2 hours.

The machining time on the M1 machine is a probabilistic quantity with normal distribution with an average of 0.6 hours/part and the standard deviation 0.04 hours/part, for the M2 machine it is a probabilistic quantity with a normal distribution with an average of 0.4 hours/part and standard deviation 0.03 hour/part, for the M3 machine is a probabilistic size with normal distribution with an average of 0.3 hours/part and standard deviation 0.02 hours/part, for the M4 machine is a probabilistic size with normal distribution with an average of 0.5 hours/part and standard deviation 0.05 hours part, for the M5 machine is a probabilistic quantity with normal distribution with an average of 0.3 hours/part and the standard deviation 0.02 hours/part and for the M6 machine is a 
probabilistic quantity with normal distribution averaging 0.25 hours/part and standard deviation 0.02 hours/part. The assembly time on M7 for subassembly 1 is a constant of 0.7 hours, for subassembly 2 (machine M8) is a constant of 0.8 hours, and for the assembly (machine M9) is 0.2 hours. Finally, the assembly is processed on M10 and M11 machines, and the processing time is a probabilistic quantity with normal distribution, with an average of 0.3 hours/part and the standard deviation 0.02 hours/part. The transfer time of subassembly 1 from machine M7 to queue 11 and that of subassembly 2 from machine M8 to queue 12 is 0.03 hours, and that of assembly from M9 to queue 13 is 0.02 hours.

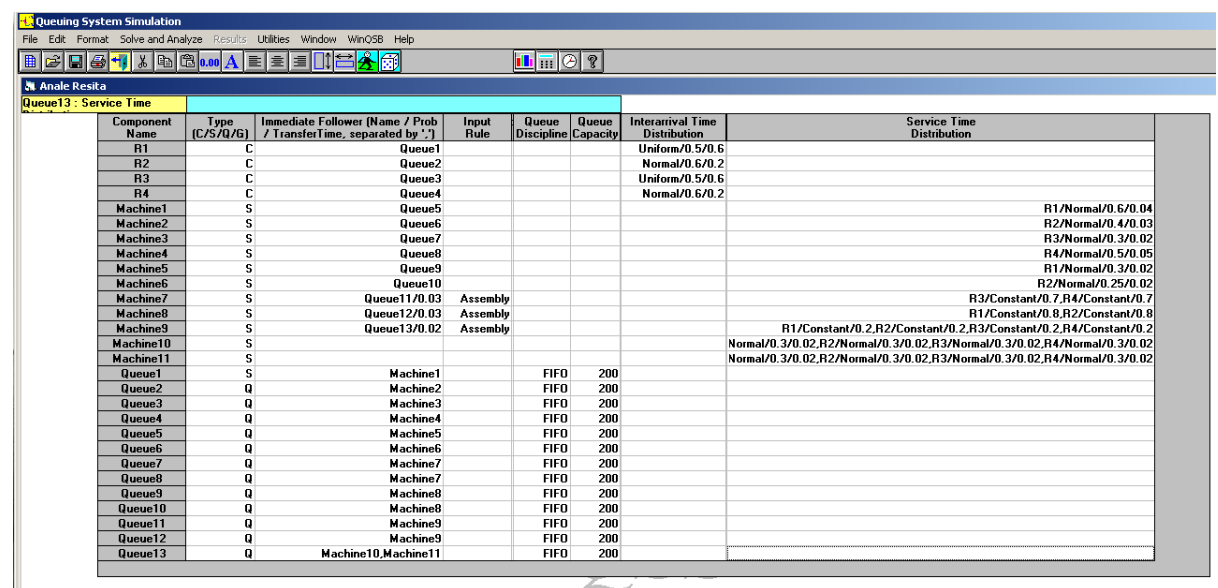

Figure 1. Input data of the problem

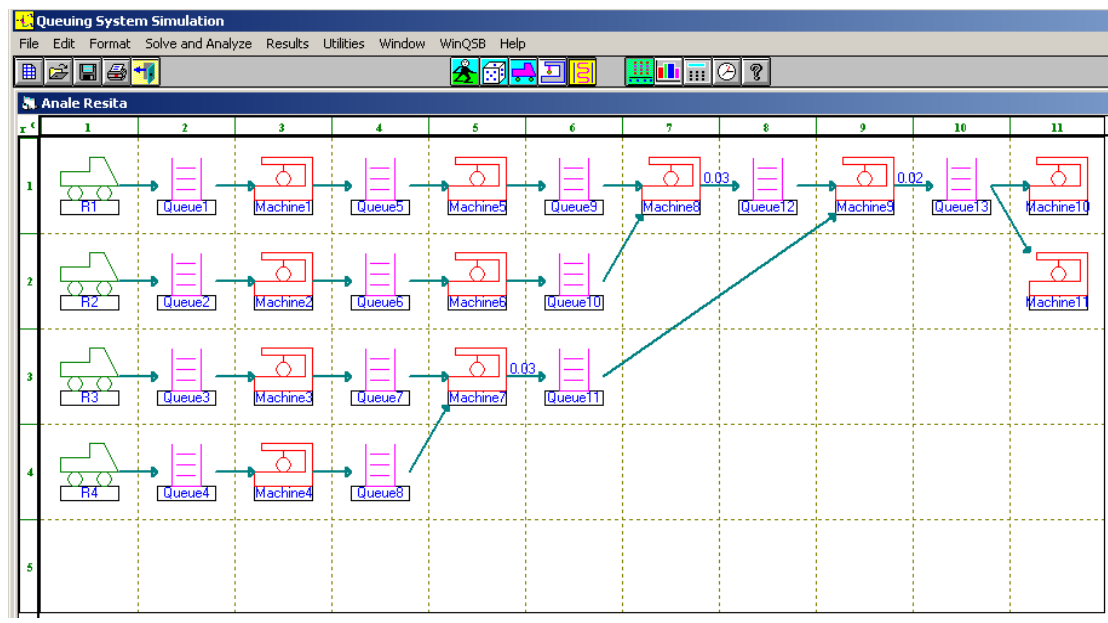

Figure 2. Graphic representation of the production system 
After entering the problem data (fig.1) the simulation of 100 hours is specified. The results are collected starting with the 20th hour of operation, in order to remove the influence of the initial conditions, when the intermediate stocks are zero [2],[5].

\subsection{Solving the problem}

The program provides results for three types of analysis: analysis of customers who have entered the system (fig.3), analysis of the use of service stations (fig.4) and queue analysis (fig.5).

\begin{tabular}{|c|c|c|c|c|c|c|}
\hline J-10-202 & Result & R1 & $\mathbf{R 2}$ & R3 & R4 & Overall \\
\hline 1 & Total Number of Arrival & 146 & 134 & 146 & 134 & 560 \\
\hline 2 & Total Number of Balking & $\mathbf{0}$ & $\mathbf{0}$ & $\mathbf{0}$ & $\mathbf{0}$ & $\mathbf{0}$ \\
\hline 3 & Average Number in the System (L) & 36.7813 & 27.3391 & 35.1105 & 12.2735 & 111.5043 \\
\hline 4 & Maximum Number in the System & 60 & 43 & $\mathbf{5 8}$ & 24 & 185 \\
\hline 5 & Current Number in the System & 60 & 42 & 58 & 23 & 183 \\
\hline 6 & Number Finished & 100 & $\mathbf{0}$ & $\mathbf{0}$ & $\mathbf{0}$ & 100 \\
\hline 7 & Average Process Time & 4.3316 & $\mathbf{0}$ & $\mathbf{0}$ & $\mathbf{0}$ & 4.3316 \\
\hline 8 & Std. Dey. of Process Time & 0.0766 & $\mathbf{0}$ & $\mathbf{0}$ & $\mathbf{0}$ & 0.0766 \\
\hline 9 & Average Waiting Time [W/q] & 56.5872 & $\mathbf{0}$ & $\mathbf{0}$ & $\mathbf{0}$ & 56.5872 \\
\hline 10 & Std. Dev. of Waiting Time & 23.4452 & $\mathbf{0}$ & $\mathbf{0}$ & $\mathbf{0}$ & 23.4452 \\
\hline 11 & Average Transfer Time & $\mathbf{0}$ & $\mathbf{0}$ & $\mathbf{0}$ & $\mathbf{0}$ & $\mathbf{0}$ \\
\hline 12 & Std. Dev. of Transfer Time & $\mathbf{0}$ & $\mathbf{0}$ & $\mathbf{0}$ & $\mathbf{0}$ & $\mathbf{0}$ \\
\hline 13 & Average Flow Time [W] & 20.1584 & $\mathbf{0}$ & $\mathbf{0}$ & $\mathbf{0}$ & 20.1584 \\
\hline 14 & Std. Dev. of Flow Time & 7.3957 & $\mathbf{0}$ & $\mathbf{0}$ & $\mathbf{0}$ & 7.3957 \\
\hline \multirow[t]{3}{*}{15} & Maximum Flow Time & 32.9214 & $\mathbf{0}$ & $\mathbf{0}$ & $\mathbf{0}$ & 32.9214 \\
\hline & Data Collection: $\mathbf{2 0}$ to & 100 hours & & & & \\
\hline & CPU Seconds = & 22.7500 & & & & \\
\hline
\end{tabular}

Figure 3. Show Customer Analysis. Current situation

After simulating the 100 hours, it is found that during the 80 hours taken into account, 146 parts R1 and R3 enter the system, and also 134 parts R2 and R4. On average per hour there are $36.78 \mathrm{R} 1$ parts in the system; 27.34 - R2; 35.11 - R3 and 12.27 - R4. The total number of products obtained by processing and assembly is 100 finished products.

The average processing time of a finished product is 4.3316 hours, with a standard deviation of 0.0766 hours. The average waiting time for a finished product is 56.5872 hours, with a standard deviation of 23.4452 hours. The average time spent in the system by a finished product is 20.1584 hours, with a standard deviation of 7.3957 hours, and the total time spent in the system by a finished product is 32.9214 hours. 


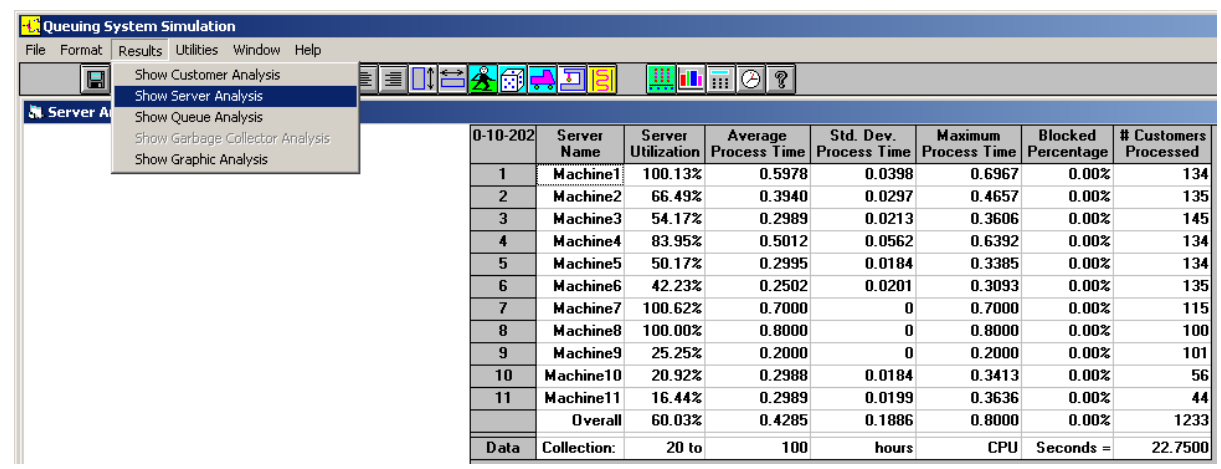

Figure 4. Show Server Analysis. Current situation

From the analysis related to the use of machines (fig.4) it is observed that the M10 and M11 machines have the lowest degree of loading, namely: $20.92 \%$ and $16.44 \%$, and the number of products processed on each of these two machines is of 56 and 44 pieces. In this case, the solution would be to remove the M11 machine, which would increase the load of the M10 machine.

Also in the table with the analysis of service stations a load of over $100 \%$ can be observed on the M1 and M7 machines, machines that can be considered "narrow place". This can be remedied by supplementing with another machine of each type.

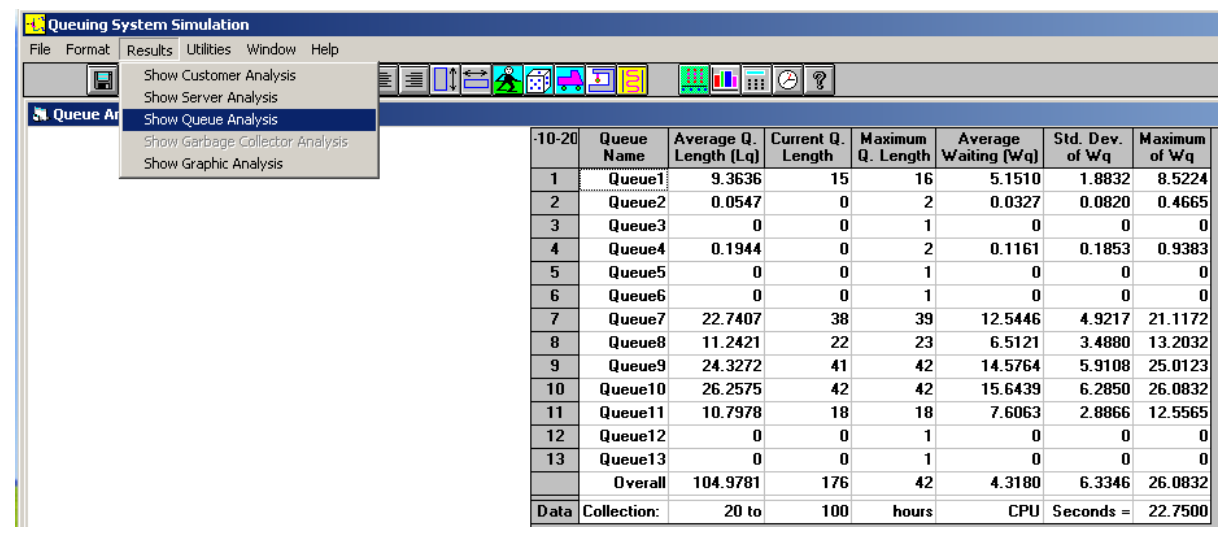

Figure 5. Show Queue Analysis. Current situation

From the analysis of intermediate stocks (fig.5) it can be seen that queue 10 has the longest average length, of 26.2575 products, as well as the longest average waiting time of 15.6439 hours. Queue 10 consists of parts R2 waiting to be assembled with parts R1 on the machine M8. The possible causes of the wait are: either the machine M8 is fully occupied, or in queue 9 there are no parts R1 to be 
assembled with the parts R2 on the machine M8. The Show Server Analysis table shows that the M8 machine has a load rate of $100 \%$, so this is the cause of the wait in the system and not the one related to queue 9, which has the second largest average length equal to 24.3272 products. To fix the problem, another M8 machine will be introduced into the system.

Following the three analyzes performed, three solutions are proposed:

1. disposal of the M11 machine;

2. additional M1 and M7 machines;

3. supplementing the M8 machine.

\subsection{Supplementation with service stations}

The production system is supplemented with three more machines (M1b, M7b and M8b) and we obtain the three analyzes presented in the section 2.1. (fig. 6, 7 and 8).

\begin{tabular}{|c|c|c|c|c|c|c|}
\hline 10-11-2020 & Result & R1 & R2 & R3 & R4 & Overall \\
\hline \begin{tabular}{|l|}
1 \\
\end{tabular} & Total Number of Arrival & 145 & 133 & 145 & 133 & 556 \\
\hline 2 & Total Number of Balking & $\mathbf{0}$ & $\mathbf{0}$ & $\mathbf{0}$ & $\mathbf{0}$ & $\mathbf{0}$ \\
\hline 3 & Average Number in the System (L) & 14.4917 & 1.1616 & 14.8868 & 0.9167 & 31.4568 \\
\hline 4 & Maximum Number in the System & 21 & 3 & 21 & 3 & 48 \\
\hline 5 & Current Number in the System & 20 & 1 & 21 & 1 & 43 \\
\hline 6 & Number Finished & 133 & $\mathbf{0}$ & $\mathbf{0}$ & $\mathbf{0}$ & 133 \\
\hline 7 & Average Process Time & 4.3435 & $\mathbf{0}$ & $\mathbf{0}$ & $\mathbf{0}$ & 4.3435 \\
\hline 8 & Std. Dev. of Process Time & 0.0785 & $\mathbf{0}$ & $\mathbf{0}$ & $\mathbf{0}$ & 0.0785 \\
\hline 9 & Average Waiting Time (W/q) & 13.1894 & $\mathbf{0}$ & $\mathbf{0}$ & $\mathbf{0}$ & 13.1894 \\
\hline 10 & Std. Dev. of Waiting Time & 4.3592 & $\mathbf{0}$ & $\mathbf{0}$ & $\mathbf{0}$ & 4.3592 \\
\hline 11 & Average Transfer Time & $\mathbf{0}$ & $\mathbf{0}$ & $\mathbf{0}$ & $\mathbf{0}$ & $\mathbf{0}$ \\
\hline 12 & Std. Dev. of Transfer Time & $\mathbf{0}$ & $\mathbf{0}$ & $\mathbf{0}$ & $\mathbf{0}$ & $\mathbf{0}$ \\
\hline 13 & Average Flow Time $[W]$ & 8.7134 & $\mathbf{0}$ & $\mathbf{0}$ & $\mathbf{0}$ & 8.7134 \\
\hline 14 & Std. Dev. of Flow Time & 2.2582 & $\mathbf{0}$ & $\mathbf{0}$ & $\mathbf{0}$ & 2.2582 \\
\hline \multirow[t]{3}{*}{15} & Maximum Flow Time & 11.8860 & $\mathbf{0}$ & $\mathbf{0}$ & $\mathbf{0}$ & 11.8860 \\
\hline & Data Collection: 20 to & 100 hours & & & & \\
\hline & CPU Seconds = & 23.9220 & & & & \\
\hline
\end{tabular}

Figure 6. Show Customer Analysis. Modified system 1

\begin{tabular}{|r|r|r|r|r|r|r|r|r|}
\hline $10-11-2020$ & $\begin{array}{c}\text { Server } \\
\text { Name }\end{array}$ & $\begin{array}{c}\text { Server } \\
\text { Utilization }\end{array}$ & $\begin{array}{c}\text { Average } \\
\text { Process Time }\end{array}$ & $\begin{array}{c}\text { Std. Dev. } \\
\text { Process Time }\end{array}$ & $\begin{array}{c}\text { Maximum } \\
\text { Process Time }\end{array}$ & $\begin{array}{c}\text { Blocked } \\
\text { Percentage }\end{array}$ & $\begin{array}{c}\text { Customers } \\
\text { Processed }\end{array}$ \\
\hline 1 & Machine1a & $54.60 \%$ & 0.5983 & 0.0383 & 0.7106 & $0.00 \%$ & 73 \\
\hline 2 & Machine1b & $53.64 \%$ & 0.5960 & 0.0442 & 0.7311 & $0.00 \%$ & 72 \\
\hline 3 & Machine2 & $66.89 \%$ & 0.4024 & 0.0311 & 0.4835 & $0.00 \%$ & 133 \\
\hline 4 & Machine3 & $54.63 \%$ & 0.2994 & 0.0203 & 0.3368 & $0.00 \%$ & 146 \\
\hline 5 & Machine4 & $82.25 \%$ & 0.4947 & 0.0506 & 0.6223 & $0.00 \%$ & 133 \\
\hline 6 & Machine5 & $53.87 \%$ & 0.2993 & 0.0212 & 0.3414 & $0.00 \%$ & 144 \\
\hline 7 & Machine6 & $41.53 \%$ & 0.2517 & 0.0209 & 0.3112 & $0.00 \%$ & 132 \\
\hline 8 & Machine7a & $56.87 \%$ & 0.7000 & 0.0003 & 0.7000 & $0.00 \%$ & 65 \\
\hline 9 & Machine7b & $58.62 \%$ & 0.7000 & 0.0001 & 0.7000 & $0.00 \%$ & 67 \\
\hline 10 & Machine8a & $69.00 \%$ & 0.8000 & 0 & 0.8000 & $0.00 \%$ & 69 \\
\hline 11 & Machine8b & $63.00 \%$ & 0.8000 & 0 & 0.8000 & $0.00 \%$ & 63 \\
\hline 12 & Machine9 & $33.00 \%$ & 0.2000 & 0.0002 & 0.2000 & $0.00 \%$ & 132 \\
\hline 13 & Machine10 & $30.47 \%$ & 0.3010 & 0.0192 & 0.3593 & $0.00 \%$ & 81 \\
\hline 14 & Machine11 & $19.20 \%$ & 0.2954 & 0.0211 & 0.3359 & $0.00 \%$ & 52 \\
\hline & Overall & $52.68 \%$ & 0.4332 & 0.1950 & 0.8000 & $0.00 \%$ & 1362 \\
\hline \hline Data & Collection: & 20 to & 100 & hours & CPU & Seconds & 23.9220 \\
\hline & & & & & & \\
\hline
\end{tabular}

Figure 7. Show Server Analysis. Modified system 1 
Following the three analyzes made on the new production system, the following conclusions can be drawn:

- the number of finished products obtained increased by 33 pieces;

- on average, there are fewer parts of each type per hour and also the maximum number of parts decreased from 60 to 21 for part R1, from 43 to 3 for part R2, 58 to 21 for the R3 part and 24 to 3 for the R4 part,

- the total time spent by a finished product decreased from 32.9214 hours to 11.886 hours;

- the average time spent on a finished product decreased from 20.1854 hours to 8.7134 hours;

- the loading of the machines is not very good, especially for the M11 machine, being $19.20 \%$, which again leads to the elimination of the M11 machine (the first solution proposed in section 2.1)

\begin{tabular}{|c|c|c|c|c|c|c|c|}
\hline 10-11-2020 & $\begin{array}{l}\text { Queue } \\
\text { Name }\end{array}$ & \begin{tabular}{|l|} 
Average Q. \\
Length (Lq)
\end{tabular} & $\begin{array}{l}\text { Current Q. } \\
\text { Length }\end{array}$ & \begin{tabular}{|l|} 
Maximum \\
Q. Length
\end{tabular} & \begin{tabular}{|c|} 
Average \\
Waiting $[W / q]$
\end{tabular} & $\begin{array}{c}\text { Std. Dev. } \\
\text { of W/q }\end{array}$ & $\begin{array}{c}\text { Maximum } \\
\text { of } W / q\end{array}$ \\
\hline 1 & Queue1 & $\mathbf{0}$ & $\mathbf{0}$ & 1 & $\mathbf{0}$ & 0 & 0 \\
\hline 2 & Queue2 & 0.0748 & $\mathbf{0}$ & 1 & 0.0450 & 0.0895 & 0.3932 \\
\hline 3 & Queue3 & 0 & $\mathbf{0}$ & 1 & 0 & 0 & 0 \\
\hline 4 & Queue4 & 0.0991 & $\mathbf{0}$ & 2 & 0.0596 & 0.0977 & 0.5852 \\
\hline 5 & Queue5 & 0 & $\mathbf{0}$ & 1 & 0 & 0 & 0 \\
\hline 6 & Queue6 & $\mathbf{0}$ & $\mathbf{0}$ & 1 & $\mathbf{0}$ & $\mathbf{0}$ & 0 \\
\hline 7 & Queue7 & 13.0546 & 19 & 20 & 7.2418 & 2.2249 & 10.3671 \\
\hline 8 & Queue8 & 0 & $\mathbf{0}$ & 1 & 0 & 0 & 0 \\
\hline 9 & Queue9 & 9.3878 & 15 & 17 & 5.2479 & 1.8171 & 8.9457 \\
\hline 10 & Queue10 & 0.0053 & $\mathbf{0}$ & 1 & 0.0032 & 0.0148 & 0.1077 \\
\hline 11 & Queue11 & 0.1331 & $\mathbf{0}$ & 2 & 0.0807 & 0.1765 & 0.7094 \\
\hline 12 & Queue12 & 1.3301 & 1 & 5 & 0.8093 & 0.9587 & 2.8988 \\
\hline \multirow[t]{2}{*}{13} & Queue13 & $\mathbf{0}$ & $\mathbf{0}$ & 1 & $\mathbf{0}$ & $\mathbf{0}$ & 0 \\
\hline & Overall & 24.0848 & 35 & 20 & 1.0157 & 2.3961 & 10.3671 \\
\hline Data & Collection: & 20 to & 100 & hours & CPU & Seconds = & 23.9220 \\
\hline
\end{tabular}

Figure 8. Show Queue Analysis. Modified system 1

\subsection{Removing a service station}

One of the solutions proposed in section 2.1 was the elimination of the M11 machine, which was also reached following the analyzes performed in section 2.2. The results obtained are almost identical to those obtained in section 2.2. The only change appears in Show Server Analysis, where the M10 machine increased the loading degree from $30.47 \%$ to $49.68 \%$, meaning it also took over the loading degree of the removed machine (fig.9). 


\begin{tabular}{|c|c|c|c|c|c|c|c|}
\hline $10-11-2020$ & $\begin{array}{l}\text { Server } \\
\text { Name }\end{array}$ & \begin{tabular}{|c|} 
Server \\
Utilization
\end{tabular} & \begin{tabular}{|c|} 
Average \\
Process Time
\end{tabular} & \begin{tabular}{|c|} 
Std. Dev. \\
Process Time
\end{tabular} & $\begin{array}{c}\text { Maximum } \\
\text { Process Time }\end{array}$ & \begin{tabular}{|c|} 
Blocked \\
Percentage
\end{tabular} & $\begin{array}{l}\text { \# Customers } \\
\text { Processed }\end{array}$ \\
\hline 1 & Machine1 a & $54.60 \%$ & 0.5983 & 0.0383 & 0.7106 & $0.00 \%$ & 73 \\
\hline 2 & Machine1b & $53.64 \%$ & 0.5960 & 0.0442 & 0.7311 & $0.00 \%$ & 72 \\
\hline 3 & Machine2 & $66.89 \%$ & 0.4024 & 0.0311 & 0.4835 & $0.00 \%$ & 133 \\
\hline 4 & Machine3 & $54.63 \%$ & 0.2994 & 0.0203 & 0.3368 & $0.00 \%$ & 146 \\
\hline 5 & Machine4 & $82.25 \%$ & 0.4947 & 0.0506 & 0.6223 & $0.00 \%$ & 133 \\
\hline 6 & Machine5 & $53.87 \%$ & 0.2993 & 0.0212 & 0.3414 & $0.00 \%$ & 144 \\
\hline 7 & Machine6 & $41.53 \%$ & 0.2517 & 0.0209 & 0.3112 & $0.00 \%$ & 132 \\
\hline 8 & Machine7a & $56.87 \%$ & 0.7000 & 0.0003 & 0.7000 & $0.00 \%$ & 65 \\
\hline 9 & Machine7b & $58.62 \%$ & 0.7000 & 0.0001 & 0.7000 & $0.00 \%$ & 67 \\
\hline 10 & Machine8a & $69.00 \%$ & 0.8000 & $\mathbf{0}$ & 0.8000 & $0.00 \%$ & 69 \\
\hline 11 & Machine8b & $63.00 \%$ & 0.8000 & $\mathbf{0}$ & 0.8000 & $0.00 \%$ & 63 \\
\hline 12 & Machine9 & $33.00 \%$ & 0.2000 & 0.0002 & 0.2000 & $0.00 \%$ & 132 \\
\hline \multirow[t]{2}{*}{13} & Machine10 & $49.68 \%$ & 0.2988 & 0.0201 & 0.3593 & $0.00 \%$ & 133 \\
\hline & Overall & $56.74 \%$ & 0.4332 & 0.1950 & 0.8000 & $0.00 \%$ & 1362 \\
\hline Data & Collection: & 20 to & 100 & hours & CPU & Seconds = & 24.0160 \\
\hline
\end{tabular}

Figure 9. Show Server Analysis. Modified system 2

A comparative graphical representation of the average and maximum processing times on the 13 machines is illustrated in Figure 10.

Server Performance

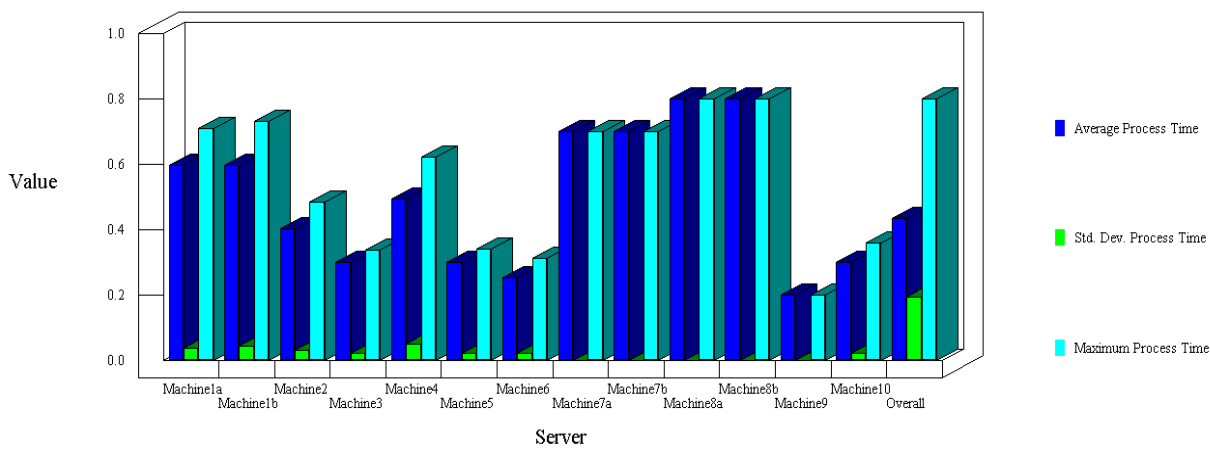

Figure 10. Graphical representation of the average and maximum processing times. Modified system 2

\subsection{Removal of an additional service station}

In section 2.2 , the production system was supplemented with three machines, namely: M1b, M7b and M8b. Following the Show Server Analysis performed in section 2.1, the M1 machine was considered a "narrow place", just like the M7 machine, although due to the fact that the number of products processed on the M1 machine is 134 , identical to that of the other machines, it would not have been appropriate to supplement with another machine in this case. 


\begin{tabular}{|c|c|c|c|c|c|c|}
\hline 10-11-2020 & Result & R1 & R2 & R3 & R4 & Overall \\
\hline 1 & Total Number of Arrival & 146 & 129 & 146 & 145 & 566 \\
\hline 2 & Total Number of Balking & $\mathbf{0}$ & $\mathbf{0}$ & $\mathbf{0}$ & $\mathbf{0}$ & $\mathbf{0}$ \\
\hline 3 & Average Number in the System (L) & 14.1330 & 1.5430 & 13.2576 & 1.8888 & 30.8225 \\
\hline 4 & Maximum Number in the System & 23 & 4 & 23 & 5 & 55 \\
\hline 5 & Current Number in the System & 22 & 1 & 21 & $\mathbf{0}$ & 44 \\
\hline 6 & Number Finished & 131 & $\mathbf{0}$ & $\mathbf{0}$ & $\mathbf{0}$ & 131 \\
\hline 7 & Average Process Time & 4.3515 & $\mathbf{0}$ & $\mathbf{0}$ & $\mathbf{0}$ & 4.3515 \\
\hline 8 & Std. Dev. of Process Time & 0.0821 & $\mathbf{0}$ & $\mathbf{0}$ & $\mathbf{0}$ & 0.0821 \\
\hline 9 & Average W/aiting Time $[W / q]$ & 12.6417 & $\mathbf{0}$ & $\mathbf{0}$ & $\mathbf{0}$ & 12.6417 \\
\hline 10 & Std. Dev. of Waiting Time & 4.5193 & $\mathbf{0}$ & $\mathbf{0}$ & $\mathbf{0}$ & 4.5193 \\
\hline 11 & Average Transfer Time & $\mathbf{0}$ & $\mathbf{0}$ & $\mathbf{0}$ & $\mathbf{0}$ & $\mathbf{0}$ \\
\hline 12 & Std. Dev. of Transfer Time & $\mathbf{0}$ & $\mathbf{0}$ & $\mathbf{0}$ & $\mathbf{0}$ & $\mathbf{0}$ \\
\hline 13 & Average Flow Time [W] & 8.0077 & $\mathbf{0}$ & $\mathbf{0}$ & $\mathbf{0}$ & $\mathbf{8 . 0 0 7 7}$ \\
\hline 14 & Std. Dev. of Flow Time & 2.5197 & $\mathbf{0}$ & $\mathbf{0}$ & $\mathbf{0}$ & 2.5197 \\
\hline \multirow[t]{3}{*}{15} & Maximum Flow Time & 12.5426 & $\mathbf{0}$ & $\mathbf{0}$ & $\mathbf{0}$ & 12.5426 \\
\hline & Data Collection: 20 to & 100 hours & & & & \\
\hline & CPU Seconds = & 24.4380 & & & & \\
\hline
\end{tabular}

Figure 11. Show Customer Analysis. Modified system 3

\begin{tabular}{|c|c|c|c|c|c|c|c|}
\hline 10-11-2020 & $\begin{array}{l}\text { Server } \\
\text { Name }\end{array}$ & \begin{tabular}{|c|} 
Server \\
Utilization
\end{tabular} & $\begin{array}{c}\text { Average } \\
\text { Process Time }\end{array}$ & \begin{tabular}{|c|} 
Std. Dev. \\
Process Time
\end{tabular} & \begin{tabular}{|c|} 
Maximum \\
Process Time
\end{tabular} & \begin{tabular}{|c|} 
Blocked \\
Percentage
\end{tabular} & \begin{tabular}{|l|} 
\# Customers \\
Processed
\end{tabular} \\
\hline 1 & Machine1 & $99.70 \%$ & 0.5997 & 0.0404 & 0.7225 & $0.00 \%$ & 133 \\
\hline 2 & Machine2 & $64.79 \%$ & 0.3987 & 0.0336 & 0.4818 & $0.00 \%$ & 130 \\
\hline 3 & Machine3 & $54.23 \%$ & 0.2971 & 0.0181 & 0.3553 & $0.00 \%$ & 146 \\
\hline 4 & Machine4 & $91.43 \%$ & 0.5010 & 0.0484 & 0.6363 & $0.00 \%$ & 146 \\
\hline 5 & Machine5 & $50.28 \%$ & 0.3002 & 0.0191 & 0.3428 & $0.00 \%$ & 134 \\
\hline 6 & Machine6 & $40.44 \%$ & 0.2508 & 0.0166 & 0.2821 & $0.00 \%$ & 129 \\
\hline 7 & Machine7a & $63.87 \%$ & 0.7000 & 0 & 0.7000 & $0.00 \%$ & 73 \\
\hline 8 & Machine7b & $63.00 \%$ & 0.7000 & $\mathbf{0}$ & 0.7000 & $0.00 \%$ & 72 \\
\hline 9 & Machine8a & $68.00 \%$ & 0.8000 & $\mathbf{0}$ & 0.8000 & $0.00 \%$ & 68 \\
\hline 10 & Machine8b & $63.00 \%$ & 0.8000 & $\mathbf{0}$ & 0.8000 & $0.00 \%$ & 63 \\
\hline 11 & Machine9 & $32.50 \%$ & 0.2000 & 0.0002 & 0.2000 & $0.00 \%$ & 130 \\
\hline \multirow[t]{2}{*}{12} & Machine10 & $49.38 \%$ & 0.3016 & 0.0203 & 0.3656 & $0.00 \%$ & 131 \\
\hline & Overall & $61.72 \%$ & 0.4373 & 0.1960 & 0.8000 & $0.00 \%$ & 1355 \\
\hline Data & Collection: & 20 to & 100 & hours & CPU & Seconds $=$ & 24.4380 \\
\hline
\end{tabular}

Figure 12. Show Server Analysis. Modified system 3

In this section the machine M1b is eliminated and the results are obtained, shown in figures 11,12 and 13 .

\begin{tabular}{|c|c|c|c|c|c|c|c|}
\hline $10-11-2020$ & \begin{tabular}{|l|} 
Queue \\
Name \\
\end{tabular} & \begin{tabular}{|l|} 
Average Q. \\
Length (Lq)
\end{tabular} & \begin{tabular}{|c|} 
Current Q. \\
Length
\end{tabular} & \begin{tabular}{l|} 
Maximum \\
Q. Length
\end{tabular} & \begin{tabular}{|c|} 
Average \\
Waiting $[\mathbf{W})$
\end{tabular} & $\begin{array}{c}\text { Std. Dev. } \\
\text { of W/q }\end{array}$ & $\begin{array}{c}\text { Maximum } \\
\text { of } \mathbf{W q}\end{array}$ \\
\hline 1 & Queue1 & 9.4093 & 16 & 16 & 5.1892 & 1.9953 & 8.3575 \\
\hline 2 & Queue2 & 0.0275 & $\mathbf{0}$ & 1 & 0.0170 & 0.0441 & 0.2329 \\
\hline 3 & Queue3 & 0 & $\mathbf{0}$ & 1 & 0 & 0 & $\mathbf{0}$ \\
\hline 4 & Queue4 & 0.9055 & $\mathbf{0}$ & 4 & 0.4996 & 0.5041 & 1.6847 \\
\hline 5 & Queue5 & 0 & 0 & 1 & 0 & 0 & $\mathbf{0}$ \\
\hline 6 & Queue6 & $\mathbf{0}$ & $\mathbf{0}$ & 1 & $\mathbf{0}$ & $\mathbf{0}$ & $\mathbf{0}$ \\
\hline 7 & Queue7 & 2.5076 & 5 & 6 & 1.3699 & 1.0190 & 2.9940 \\
\hline 8 & Queue8 & 0.0738 & 0 & 2 & 0.0404 & 0.1125 & 0.5614 \\
\hline 9 & Queue9 & 1.0720 & 3 & 4 & 0.6403 & 0.6987 & 2.1803 \\
\hline 10 & Queue10 & 0.4677 & $\mathbf{0}$ & 3 & 0.2948 & 0.3731 & 1.2650 \\
\hline 11 & Queue11 & 8.9183 & 14 & 16 & 5.0259 & 2.7902 & 8.9297 \\
\hline 12 & Queue12 & 0.0252 & $\mathbf{0}$ & 1 & 0.0154 & 0.0672 & 0.4968 \\
\hline \multirow[t]{2}{*}{13} & Queue13 & 0.0000 & 0 & 1 & 0.0000 & 0.0003 & 0.0035 \\
\hline & Overall & 23.4068 & 38 & 16 & 0.9952 & 2.0415 & 8.9297 \\
\hline Data & Collection: & 20 to & 100 & hours & CPU & Seconds $=$ & 24.4380 \\
\hline
\end{tabular}

Figure 13. Show Queue Analysis. Modified system 3 
A comparative graphic image of the average and maximum processing times on the 12 machines is presented in fig. 14 . Also, in fig. 15 are represented graphically the average and maximum values of the intermediate stocks, respectively of the average and maximum lengths of the queues in the system.

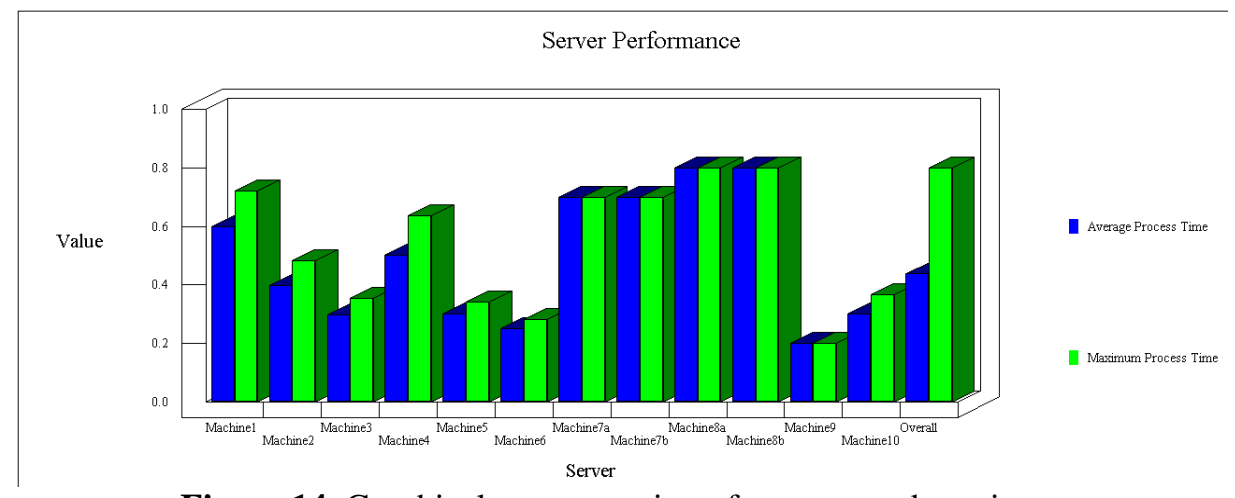

Figure 14. Graphical representation of average and maximum processing times. Modified system 3

Queue Performance

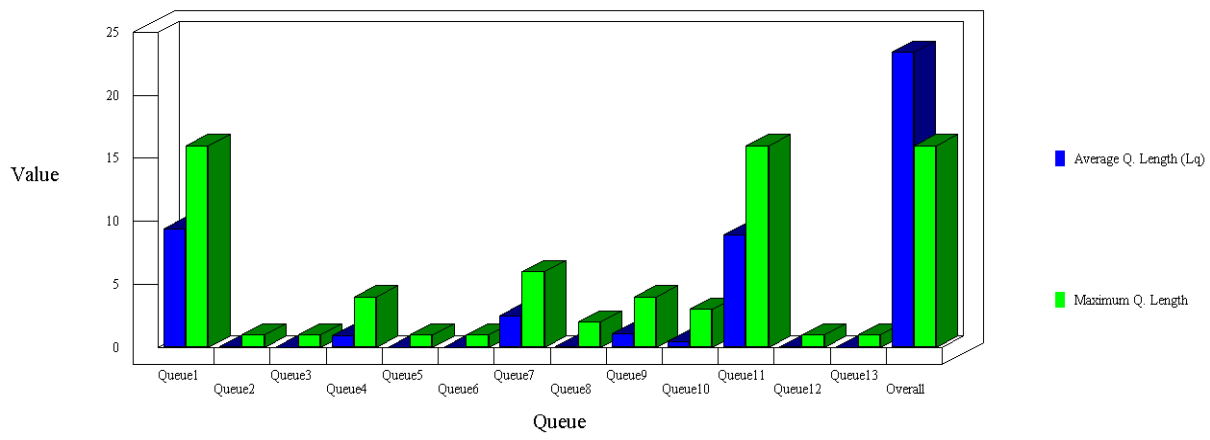

Figure 15. Graphical representation of average and maximum Q lengths. Modified system 3

In the table with comparative results in Figure 16, with the elimination of the M1b machine, the total number of finished products decreased from 133 to 131. 


\begin{tabular}{|c|c|c|c|c|}
\hline & $\begin{array}{c}\text { The current } \\
\text { system }\end{array}$ & $\begin{array}{c}\text { Modified } \\
\text { system } 1\end{array}$ & $\begin{array}{l}\text { Modified } \\
\text { system } 2\end{array}$ & $\begin{array}{c}\text { Modified } \\
\text { system } 3\end{array}$ \\
\hline \multicolumn{5}{|l|}{ Show Customer Analysis } \\
\hline Number Finished & 100 & 133 & 133 & 131 \\
\hline Average Process Time & 4.3316 & 4.3435 & 4.3435 & 4.3515 \\
\hline Average Waiting Time & $\mathbf{5 6 . 5 8 7 2}$ & 13.1894 & 13.1894 & 12.6417 \\
\hline Average Flow Time & 20.1584 & 8.7134 & 8.7134 & 8.0077 \\
\hline \multicolumn{5}{|l|}{ Show Server Analysis } \\
\hline Mla-Server Utilization/Customers Processed & $100.13 / 134$ & $54.6 / 73$ & $54.6 / 73$ & $99.7 / 133$ \\
\hline Mlb-Server Utilization/Customers Processed & - & $53.64 / 72$ & $53.64 / 72$ & - \\
\hline M2-Server Utilization/Customers Processed & $66.49 / 135$ & $66.89 / 133$ & $66.89 / 133$ & $64.79 / 130$ \\
\hline M3-Server Utilization/Customers Processed & $54.17 / 145$ & $54.63 / 146$ & $54.63 / 146$ & $54.23 / 146$ \\
\hline M4-Server Utilization/Customers Processed & $83.95 / 134$ & $82.25 / 133$ & $82.25 / 133$ & $91.43 / 146$ \\
\hline M5-Server Utilization/Customers Processed & $50.17 / 134$ & $53.87 / 144$ & $53.87 / 144$ & $50.28 / 134$ \\
\hline M6-Server Utilization/Customers Processed & $42.23 / 135$ & $41.53 / 132$ & $41.53 / 132$ & $40.44 / 129$ \\
\hline M7a-Server Utilization/Customers Processed & $100.62 / 115$ & $56.87 / 65$ & $56.87 / 65$ & $63.87 / 73$ \\
\hline M7b-Server Utilization/Customers Processed & - & $58.62 / 67$ & $58.62 / 67$ & $63 / 72$ \\
\hline M8a-Server Utilization/Customers Processed & $100 / 100$ & $69 / 69$ & $69 / 69$ & $68 / 68$ \\
\hline M8b-Server Utilization/Customers Processed & - & $63 / 63$ & $63 / 63$ & $63 / 63$ \\
\hline M9-Server Utilization/Customers Processed & $25.25 / 101$ & $33 / 132$ & $33 / 132$ & $32.5 / 130$ \\
\hline Ml0-Server Utilization/Customers Processed & $20.92 / 56$ & $30.47 / 81$ & $49.68 / 133$ & $49.38 / 131$ \\
\hline Mll-Server Utilization/Customers Processed & $16.44 / 44$ & $19.2 / 52$ & - & - \\
\hline
\end{tabular}

Figure 16. Comparative results

\section{Conclusion}

The waiting theory shows us that the average time spent by a consumer in the system consists of the average time spent in the queue and the time needed to serve. In this case, where the consumer in the waiting system is a finished product, the average time spent in the system is obtained by following the path taken by the part to achieve the finished product.

In the present paper we started from a production system consisting of 11 machines (servers), on which 100 finished products were processed and assembled. Following the supplementation of the system with 3 machines, it was observed that as the loading degree of the machines decreases (server utilization coefficient), the average downtime of the finished products in the system decreases, as well as the average waiting time and the number of finished products increases. But this decrease in the degree of loading of the machines also led to the situation where most of the queues are non-existent, in which case no intermediate stocks are needed due to the processing times of the parts or not enough parts enter the system. 


\section{References}

[1] Amariei O.I., Contribuții privind modelarea, simularea și optimizarea fluxurilor de producție utilizând programe dedicate, Editura Politehnica Timișoara, 2014.

[2] Amariei O.I., Aplicații ale programului WinQSB în simularea sistemelor de producție, Editura Eftimie Murgu, Reșița, 2009.

[3] Amariei O.I., Dumitrescu D.C., Fourmaux D., Analysis and Behaviour Understanding of a Production System, Analele Universitatii „Eftimie Murgu" Resita, Fascicula de Inginerie, 16(1), 2009, pp. 21-28.

[4] Amariei O.I., Frunzăverde D., Popovici Gh.. Hamat C.O., WinQSB simulation software-a tool for professional development, Procedia-Social and Behavioral Sciences, 1(1), 2009, pp. 2786-2790.

[5] Blăjină, O.A., Decizii optime în management cu WinQSB 2.0, Vol.1, Editura Albastră, Cluj-Napoca, 2011.

[6] Gorunescu F., Prodan A., Modelare stochastică și simulare, Editura Albastră, Cluj-Napoca, 2001.

[7] Kikolsk M., Study of Production Scenarios with the Use of Simulation Models, $7^{\text {th }}$ International Conference on Engineering, Project, and Production Management, Procedia Engineering 182, 2017, 321 - 328.

[8] Rațiu-Suciu C., Luban F., Hîncu D., Ciocoiu N., Modelare economică. Ediția a doua, Editura ASE București, 2009.

[9] Rațiu-Suciu C., Modelarea \& simularea proceselor economice. Teorie și practică. Ediția a treia, Editura Economică, 2003.

Addresses:

- Lect. Dr. Eng. Olga-Ioana Amariei, Babeș-Bolyai University, Faculty of Engineering, Piaţa Traian Vuia, nr. 1-4, 320085, Reşiţa, o.amariei@uem.ro

- Prof. Dr. Eng. Codruța-Oana Hamat, Babeș-Bolyai University, Faculty of Engineering, Piaţa Traian Vuia, nr. 1-4, 320085, Reşiţa, c.hamat@uem.ro ( ${ }^{*}$ corresponding author) 